\title{
Lixiviação de nutrientes em solo cultivado com aplicação de água residuária de suinocultura
}

\author{
Cacea F. Maggi ${ }^{1}$, Paulo S. L. de Freitas ${ }^{2}$, Silvio C. Sampaio ${ }^{3}$ \& Jonathan Dieter ${ }^{3}$
}

\begin{abstract}
RESUMO
O bjetivou-se neste trabalho avaliar os impactos do percolado em lisímetros de drenagem com a aplicação de diferentes taxas de áqua residuária de suinocultura (ARS) durante o ciclo da cultura da soja. Conduziuse 0 experimento no Núcleo Experimental de Engenharia Agrícola da U N IO ESTE, em solo foi classificado como Latossolo Vermelho distroférrico. A área dispunha 24 lisímetros de drenagem, na qual se semeou a cultura da soja, cultivar CD 214. Porém, sete dias antes da semeadura, em única aplicação foram

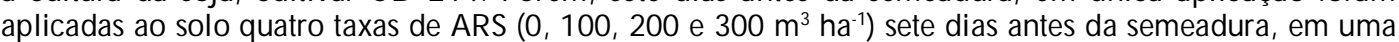
única aplicação, combinadas com duas adubações na semeadura (com adição e sem adição da adubação recomendada na semeadura) e três repetições por tratamento. Foram realizadas três coletas do percolado em cada parcela experimental, a primeira aos 40 dias após a semeadura (DAS), a segunda aos 72 DAS e a terceira no final do ciclo da cultura (117 D AS). Avalioram-se pH, cálcio, magnésio, potássio, fósforo e nitrogênio total. Com base nos resultados observou-se que os valores de $\mathrm{pH}$ e $\mathrm{Mg}$ no percolado não sofreram influência pela aplicação de ARS e adubação. As concentrações de $\mathrm{K}^{+}, \mathrm{P}$ e $\mathrm{Ca}^{+2}$ no percolado foram maiores para taxas mais elevadas de ARS.
\end{abstract}

Palavras-chave: lisímetros, efluente, poluição do solo

\section{Leaching of nutrients in cultivated soils under application of residual water of pig farming}

\begin{abstract}
This work aimed to evaluate the impacts on leachate from drainage lysimeters receiving application of different rates of pig farming residual water (PRW) during soybean crop cycle. The experiment was conducted at the Agricultural Engineering Experimental field of UNIOESTE. The soil was classified as Rhodic Ferralsols. There were twenty-four drainage lysimeters where soybean cultivar CD 214 was sown. Four PRW rates $\left(0 ; 100 ; 200\right.$ and $\left.300 \mathrm{~m}^{3} \mathrm{ha}^{-1}\right)$ were applied to the soil seven days before sowing in a single application combined with two fertilizations (with and without recommended dose) during sowing, and three repetitions per treatment. Three leachate collections were carried out in each experimental plot. The first was conducted 40 days after sowing (DAS); the second at 72 DAS, and the third at the end of crop cycle (117 DAS). pH, calcium, magnesium, potassium, phosphorus, and total nitrogen were evaluated. Based on the results, it was possible to observe that $\mathrm{pH}$ and $\mathrm{Mg}$ values in the leachate did not suffer influence of PRW application and fertilization. $\mathrm{K}^{+}, \mathrm{P}$ and $\mathrm{Ca}^{+2}$ in the leachate were higher for higher PRW rates.
\end{abstract}

Key words: Iysimeter, effluent, soil pollution

\footnotetext{
${ }^{1}$ DEA/U EM, Av. Colombo, 5790,CEP 87020-900, Maringá, PR. Fone: (44) 3675-1779. E-mail: cf_maggi@yahoo.com.br

2 DAG/ UEM, Av. Colombo, 5790,CEP 87020-900, Maringá, PR. Fone: (44) 3261-8916. E-mail: pslfreitas@uem.br

3 UNIO ESTE/CASCAVEL/PG EA RI/RH ESA, Rua Universitária 2069, CEP 85819-110. Cascavel, PR. Fone: (45) 3220-3262. E-mail: ssampaio@unioeste.br; jonathan_dieter@yahoo.com.br
} 


\section{INTRODUÇÃO}

A utilização de águas residuárias de suinocultura em lavouras, como fertilizante ou forma de descarte, é uma prática rotineira e, às vezes, a única fonte de nutrientes à cultura, sendo esta forma de amenizar os custos de produção, visando ao aumento do lucro das pequenas propriedades.

Segundo Freitas et al. (2004) a disposição de água residuária de animais no soloé muito utilizada, principalmente na Europa e nos Estados Unidos, para fertilização de solos cultivados. Sua aplicação ao solo busca uma determinação adequada para a água residuária baixar custos na sua disposição final, além de proporcionar a melhoria da fertilidade do solo.

Freitas et al. (2004) avaliaram o efeito da aplicação de quatro lâminas de água e água residuária de suinocultura, bruta e peneirada, sobre os componentes de produção da cultura do milho (Zea mays L.). As concentrações foram de DBO de 1.111 $\mathrm{mg} \mathrm{L}^{-1}$ para a água residuária bruta e de $1.072 \mathrm{mg} \mathrm{L}^{-1}$ para a água residuária peneirada. Os autores constataram que o uso da água residuária de suinocultura aumentou significativamente a produtividade, altura de plantas e índice e massa de espigas, em que a produtividade para os tratamentos com água residuária foi aproximadamente $58 \%$ superior à testemunha.

Queiroz et al. (2004) avaliaram o efeito da intensiva aplicação de água residuária de suinocultura (ARS) nas características químicas de um solo Podzólico Vermelho-Amarelo, cultivado com quatro diferentes espécies de gramíneas forrageiras, a uma taxa de $800 \mathrm{~kg} \mathrm{ha}^{-1} \mathrm{~d}^{-1}$ de $\mathrm{DBO}_{5}$, e observaram que a aplicação de ARS proporcionou um acúmulo de $\mathrm{P}, \mathrm{K}, \mathrm{Na}$ e Zn no solo, na camada de 0-20 cm, enquanto as concentrações de $\mathrm{Mg}$ e $\mathrm{Cu}$ reduziram-se e a de Ca se manteve igual.

Durigon et al. (2002) constaram em um estudo com aplicação de água residuária de suinocultura em pastagem natural, no Rio Grande do Sul, que houve maior produção de matéria seca na pastagem em todas as estações do ano com a aplicação da água residuária mas os incrementos foram maiores no verão e na primavera, quando ocorre maior insolação e as temperaturas são mais altas, favorecendo o crescimento vegetativo. A dose de $20 \mathrm{~m}^{3} \mathrm{ha}^{-1}$ proporcionou aumentos de $109 \%$ na produção de matéria seca ao final de 48 meses; já com a dose de $40 \mathrm{~m}^{3} \mathrm{ha}^{-1}$ houve um acréscimo de $155 \%$, porém os autores relataram a possível contaminação ambiental causada por essa dose 40 $\mathrm{m}^{3} \mathrm{ha}^{-1}$.

Anami et al. (2008) estudaram o processo de percolação de íons nitrato e fosfato em coluna de solo e verificaram que o íon nitrato apresentou elevado potencial de percolação, ao contrário do que ocorreu com o íon fosfato, que apresentou baixo potencial de contaminação. Como o cálcio é mais fortemente absorvido que o amônio, potássio e magnésio, sua percolação não é tão intensa e, na verdade, não chega a ser preocupante, em termos de perdas.

Brito et al. (2007) avaliando a qualidade do lixiviado de solos submetidos à aplicação de vinhaça, observaram que os índices de condutividade elétrica (CE) no lixiviado aumentaram com o aumento da aplicação sem, porém, apresentarem problemas de contaminação do lençol freático.
Caovilla et al. (2005) estudando a percolação de nutrientes em colunas de solo cultivado com soja e irrigado com água residuária de suinocultura, notaram que o nitrato apresentou maior mobilidade no processo de lixiviação, seguido da concentração de sais totais e, posteriormente, do potássio, proporcionalmente aos tratamentos avaliados. De modo geral, o tratamento que apresentou $75 \%$ de água residuária revelou, nos lixiviados, os maiores níveis de concentração de nitrato, potássio e concentração de sais.

Barros et al. (2005), avaliando as características químicas de solo em função da adição de água residuária de suinocultura, observaram que os índices de condutividade elétrica no solo apresentaram aumento com valor mínimo de $108,6 \mathrm{dS} \mathrm{m}^{-1}$, nas condições de maiores temperaturas e máximo de $166,66 \mathrm{dS} \mathrm{m}^{-1}$, em menores temperaturas.

Ante o contexto, esse trabalho teve como objetivo avaliar os impactos do percolado em lisímetros de drenagem com a aplicação de diferentes taxas de água residuária de suinocultura durante o ciclo da cultura da soja.

\section{MATERIAL E MÉTODOS}

O experimento foi conduzido no Núcleo Experimental de Engenharia Agrícola - NEEA, do Centro de Ciências Exatas e Tecnológicas da Universidade Estadual do Oeste do Paraná, Campus de Cascavel, PR, situado no km 95 da BR 467. A localização geográfica está definida pelas coordenadas $24^{\circ} 48^{\prime}$ de latitude Sul e $53^{\circ} 26^{\prime}$ 'de longitude Oeste, altitude de 760 metros.

O clima é do tipo subtropical úmido (Cfa), com precipitação média anual de $1.800 \mathrm{~mm}$, verões quentes, geadas pouco frequentes e tendência de concentração de chuvas nos meses de verão, sem estação seca definida. O município apresenta temperatura média de $20^{\circ} \mathrm{C}$ e umidade relativa do ar média de $75 \%$.

O solo da área experimental foi classificado como Latossolo Vermelho distroférrico típico, com relevo suave a ondulado e textura muito argilosa, com composição de 5,90\% de areia, 14,73\% de silte e 79,37\% de argila (EMBRAPA, 1999).

$\mathrm{Na}$ área foram conduzidos, anteriormente, quatro experimentos consecutivos com aplicação de água residuária de suinocultura (ARS).

No primeiro experimento aplicou-se ARS na cultura da soja via água de irrigação por gotejamento em ambiente protegido e, no segundo; instalaram lisímetros de drenagem para verificar os efeitos da aplicação ARS na cultura do milho, em ambiente protegido e com sistema de irrigação por gotejamento. Após a implantação dos lisímetros, fez-se a caracterização química do solo da área e, visto que os resultados apresentaram heterogeneidade em relação à fertilidade, blocos foram estabelecidos, dividindo-se a área de modo a garantir a correção da acidez e adubação química conforme as necessidades dos blocos, enquanto no terceiro experimento, se avaliaram os efeitos da ARS na cultura da soja em ambiente protegido com sistema de irrigação localizada, por outro lado foram avaliados 
Tabela 1. Resultado da análise química composta do solo coletado nos lisímetros para adubação

\begin{tabular}{|c|c|c|c|c|c|c|c|c|c|c|c|c|c|c|c|}
\hline \multirow{2}{*}{$\begin{array}{c}\mathrm{pH} \\
\mathrm{CaCl}_{2}\end{array}$} & MO & $\mathrm{H}+\mathrm{AL}^{+3}$ & $\mathrm{AL}^{+3}$ & $\mathbf{K}^{+}$ & $\mathrm{Ca}^{+2}$ & $\mathrm{Mg}^{+2}$ & SB & CTC & \multirow{2}{*}{$\begin{array}{l}\mathbf{V} \\
\%\end{array}$} & $P$ & $\mathrm{Na}$ & $\mathrm{Cu}$ & $\mathrm{Fe}$ & $M n$ & $\mathrm{Zn}$ \\
\hline & $\mathrm{g} \mathrm{dm}^{-3}$ & \multicolumn{7}{|c|}{$\mathrm{cmol}_{\mathrm{c}} \mathrm{dm}^{-3}$} & & \multicolumn{6}{|c|}{$\mathrm{mg} \mathrm{dm}^{-3}$} \\
\hline 6 & 18,11 & 3,42 & 0 & 0,37 & 6,68 & 4,18 & 11,23 & 14,65 & 76,6 & 4,73 & 3,52 & 5,2 & 11,86 & 7,15 & 0,89 \\
\hline
\end{tabular}

os efeitos da ARS na cultura da aveia preta para produção de grãos, em ambiente aberto e sem sistema de irrigação.

As amostras de solo de cada lisímetro foram coletadas na camada $0-60 \mathrm{~cm}$; e todas elas foram homogenizadas para que formassem uma única amostra composta para determinação da análise química do solo. A adubação foi feita com base na análise química para a cultura da soja (Tabela 1 ).

$\mathrm{Na}$ área experimental havia 24 lisímetros de drenagem, construídos de acordo com a metodologia da FAO (1982). Os lisímetros foram distribuídos em três linhas com oito lisímetros, espaçados $0,6 \mathrm{~m}$ na largura e $0,4 \mathrm{~m}$ no comprimento; o volume do lisímetro era de $1 \mathrm{~m}^{3}$ e área de $1,60 \mathrm{~m}^{2}$ (profundidade de 0,91 m e diâmetro superior de 1,43 m) compreendendo uma parcela experimental. Desta forma havia cada parcela, quatro linhas da cultura, em que as duas linhas centrais foram consideradas área útil e as outras duas, uma em cada lateral dos lisímetros, com função de bordadura.

Conduziu-se este experimento durante o período de novembro de 2007 a abril de 2008.

No dia 13 de dezembro de 2007 semeou-se soja, cultivar CD 214, COODETEC - Cooperativa Central de Pesquisa Agrícola de ciclo precoce, 117 dias e se fez semeadura manual, após a colheita da aveia, na densidade de 15 sementes por metro linear, espaçadas entre linhas de 45 centímetros, proporcionando um estande de 300.000 plantas por hectare; enfim, realizou-se a semeadura.

Utilizou-se herbicida glifosato para o controle de plantas daninhas, aplicado 10 dias antes da semeadura e, durante o ciclo da cultura, o controle das mesmas foi feito por meio da capina manual, sempre que necessário. Não foram realizados outros tratos culturais na cultura da soja.

Coletou-se a água residuária de suinocultura numa propriedade rural na qual está instalado um Biossistema Integrado, localizado no município de Toledo, PR. A água residuária coletada foi tratada em um biodigestor seguido de um tanque de sedimentação e lagoa de estabilização, sendo a tubulação de saída, o ponto de coleta. A análise química da água residuária se encontra na Tabela 2.

Aplicou-se ARS manualmente, sete dias antes da semeadura, com o auxílio de um regador, em uma única dose, tomando-se o máximo cuidado para que não houvesse escoamento da água residuária da parcela.

Utilizaram-se quatro taxas de aplicação de ARS, as quais foram definidas como base em estudos realizados em 2005 (Prior et al., 2009) e 2006 (Smanhotto et al., 2010); assim, as taxas de ARS foram de $0,100,200$ e $300 \mathrm{~m}^{3}$ ha $^{-1}$ aplicadas ao solo sete dias antes da semeadura.

Além das taxas de aplicação avaliou-se também o efeito da adubação na semeadura e se aplicaram $400 \mathrm{~kg} \mathrm{ha}^{-1}$ do formulado 0-20-10 de NPK, de acordo com a análise do solo apresentada na Tabela 1.
Tabela 2. Caracterização da água residuária de suinocultura utilizada no experimento

\begin{tabular}{|c|c|}
\hline Parâmetros & \\
\hline $\mathrm{pH}\left(\mathrm{CaCl}_{2}\right)$ & 7,7 \\
\hline Condutividade elétrica ( $\mathrm{dS} \mathrm{m}^{-1}$ ) & 5,43 \\
\hline Turbidez (NTU) & 393,00 \\
\hline $\mathrm{DBO}\left(\mathrm{mg} \mathrm{L}^{-1}\right)$ & 945,78 \\
\hline $\mathrm{DQO}\left(\mathrm{mg} \mathrm{L}^{-1}\right)$ & 1322,13 \\
\hline Amônia (mg L ${ }^{-1}$ ) & 466,45 \\
\hline Nitrogênio total $\left(\mathrm{mg} \mathrm{L}^{-1}\right)$ & 887,00 \\
\hline Nitrato $\left(\mathrm{mg} \mathrm{L}^{-1}\right)$ & 2,18 \\
\hline Nitrito $\left(\mathrm{mg} \mathrm{L}^{-1}\right)$ & 2,25 \\
\hline Fósforo total (mg L $\left.{ }^{-1}\right)$ & 108,62 \\
\hline Orto fosfato solúvel ( $\mathrm{mg} \mathrm{L}^{-1}$ ) & 76,15 \\
\hline Potássio (mg L $\left.{ }^{-1}\right)$ & 462,11 \\
\hline Sódio $\left(\mathrm{mg} \mathrm{L}^{-1}\right)$ & 26,00 \\
\hline Cálcio (mg L $\left.{ }^{-1}\right)$ & 38,60 \\
\hline Magnésio $\left(\mathrm{mg} \mathrm{L}^{-1}\right)$ & 39,12 \\
\hline Cobre (mg L-1) & 0,25 \\
\hline Znco $\left(\mathrm{mg} \mathrm{L}^{-1}\right)$ & 0,20 \\
\hline
\end{tabular}

Os tratamentos nas parcelas foram distribuídos obedecendose à ordem estabelecida por Prior et al. (2009), que sorteou aleatoriamente a disposição dos tratamentos em cada bloco.

Os tratamentos foram distribuídos nas parcelas da área experimental com três repetições.

Para a análise química do percolado o delineamento experimental foi em blocos casualizados em esquema fatorial (4 x 2) e subparcelas no tempo, ou seja, foram usados: quatro taxas de ARS $\left(0,100,200\right.$ e $\left.300 \mathrm{~m}^{3} \mathrm{ha}^{-1}\right)$ e dois níveis de adubação (com ou sem adubação química na semeadura), em que as subparcelas foram constituídas por três diferentes datas de coletas (40, 72 e 117 DAS), com três repetições.

Antes da realização da análise de variância (ANOVA), foi feita a análise descritiva dos dados e a verificação da normalidade dos erros. Os parâmetros que não apresentaram distribuição normal dos erros foram transformados e, posteriormente, submetidos à análise de variância.

Para verificação da normalidade dos dados utlizou-se o software MINITAB R15 e para as análises de variância o software SISVAR (Ferreira, 2000).

Os dados foram submetidos à análise de variância para verificação de sua significância; em relação aos que apresentaram significância, procedeu-se à análise de regressão.

Três coletas foram realizadas e os pontos coletores de cada lisímetro eram abertos para essa operação a coleta das amostras. Em cada ponto de coleta do percolado havia um recipiente plástico com capacidade para $8 \mathrm{~L} \mathrm{e}$, à medida em que se completava a sua capacidade, era transposto para outro recipiente plástico correspondente a cada lisímetro, de forma a homogeneizar as amostras percoladas; em seguida, homogeneizou-se e se quantificou o volume percolado, as amostras foram armazenadas em frascos plásticos de $1000 \mathrm{~mL}$ e encaminhadas ao Laboratório de Saneamento Ambiental da Universidade Estadual do Oeste do Paraná - UNIOESTE, 
Campus de Cascavel, onde se determinou o $\mathrm{pH}$, condutividade elétrica, nitrogênio total, nitrato e fósforo. As metodologias utilizadas foram: APHA (1998) e Tedesco et al. (1995). As análises de potássio, magnésio e cálcio, foram feitas pela utilizando-se espectrofotometria de absorção atômica de chama.

A precipitação pluvial total ocorrida no período do experimento foi de 550,4 mm; pode-se observar, na Figura 1, a distribuição da precipitação durante o experimento.

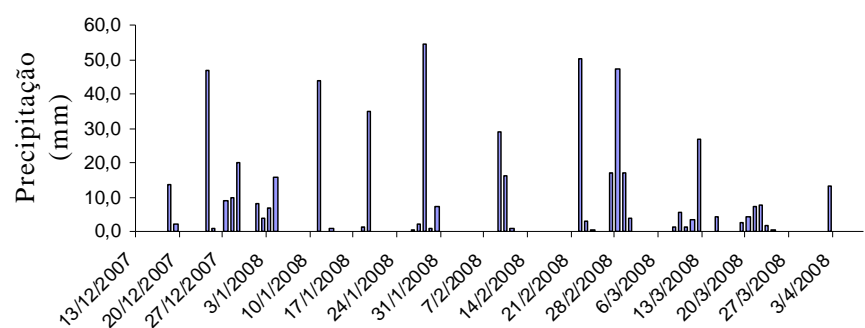

Figura 1. Distribuição da precipitação pluvial durante 0 experimento

\section{RESULTADOS E DISCUSSÃO}

Pela análise de variância, o valor de $\mathrm{F}$ foi significativo somente para a variável DAS; para os fatores ARS, AD (adubação) e as interações AD*ARS, AD*DAS e ARS*DAS F foi não significativo a nível de $5 \%$.

Os valores de $\mathrm{pH}$ do percolado não variaram em função dos tratamentos com ARS, bem como com a adição ou não da adubação. Resultados semelhantes foram encontrados por Smanhotto et al. (2010), Caovilla et al. (2005) e Gomes et al. (2004) que não observaram diferenças significativas nos valores de $\mathrm{pH}$ para o percolado para os tratamentos com ARS e adubação. Também, Duarte et al. (2008) avaliaram o efeito da aplicação de efluente doméstico tratado e água de abastecimento público na cultura do pimentão e verificaram que o uso da água residuária não provocou alterações significativas no $\mathrm{pH}$.

Ocorreu um acréscimo nos valores de $\mathrm{pH}$ do percolado, ao longo das coletas (Figura 2).

De acordo com a Figura 2, pôde-se observar que os valores de $\mathrm{pH}$ do percolado sofreram um pequeno aumento do decorrer das coletas.

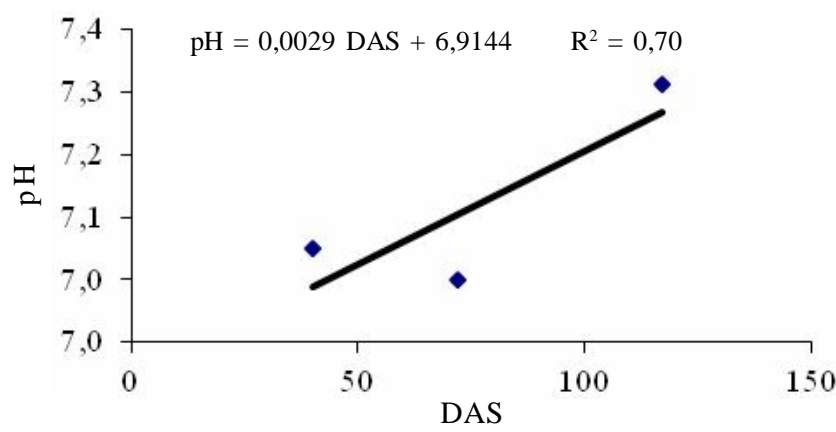

Figura 2. Valores médios de $\mathrm{pH}$ no material percolado de acordo com as diferentes coletas

\section{Cálcio}

Os efeitos das variáveis sobre a concentração de cálcio foram significativos para adubação, para as taxas de aplicação de ARS e para DAS.

O teor de cálcio no material percolado foi maior para os tratamentos que receberam adubação $55,51 \mathrm{mg} \mathrm{L}^{-1}$; em relação ao não adubado, $46,53 \mathrm{mg} \mathrm{L}^{-1} \mathrm{e}$ foram estatisticamente a nível de $5 \%$ de probabilidade, o que pode ter acontecido em virtude do mesmo não sendo o formulado à base de $\mathrm{Ca}$, apresenta um percentual desse elemento em sua composição, em torno de $11 \%$, e este fator contribuiu para tal aumento das concentrações de Ca nos tratamentos que receberam adubação na semeadura.

As concentrações de $\mathrm{Ca}$ no percolado aumentaram de acordo com as taxas de ARS (Figura 3A).
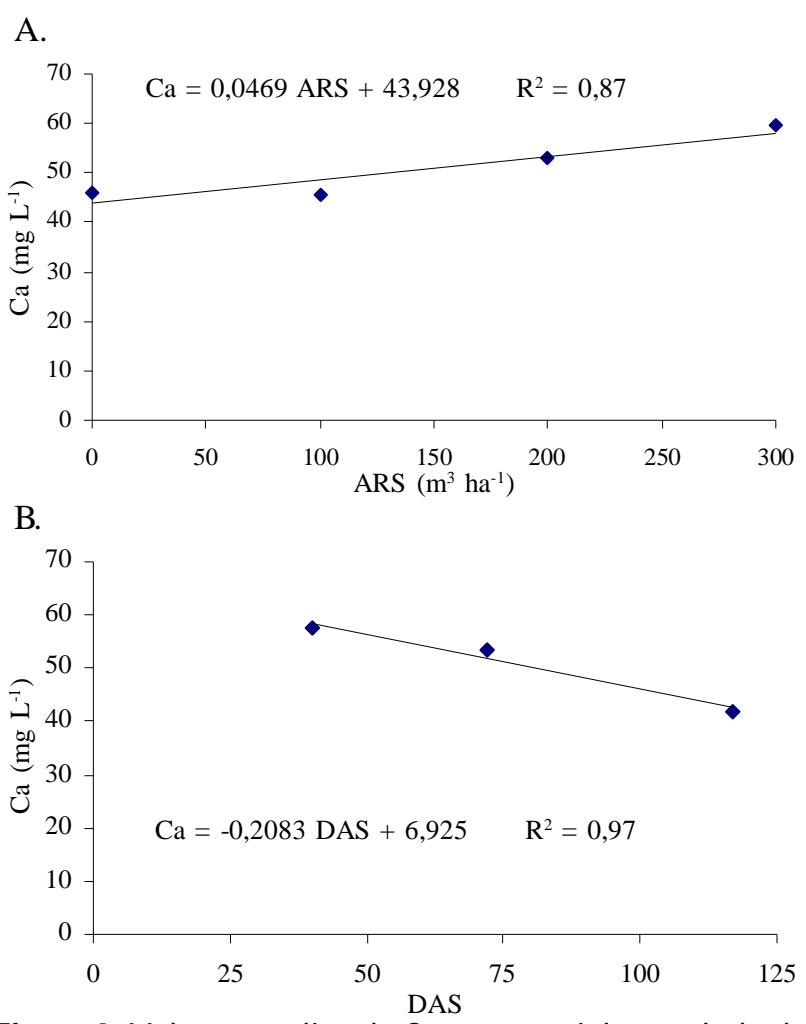

Figura 3. Valores médios de Ca no material percolado de acordo com as diferentes taxas de ARS (A) e de datas de $\operatorname{coletas}(B)$

Como o cálcio no solo é mais fortemente adsorvido que amônio, potássio e magnésio, sua lixiviação não é tão intensa e, na verdade, não chega a ser preocupante, em termos de perda. Segundo Furtini Neto et al. (2001) a aplicação de resíduos orgânicos ao solo aumenta a lixiviação de cálcio. Na Figura 3A é possível verificar que as concentrações de cálcio no percolado aumentaram de acordo com o aumento das taxas de ARS, comprovando que os resíduos orgânicos aumentam a lixiviação pelo fato de que a água residuária pode ocasionar elevação do pH favorecendo a mineralização, aumentando a liberação de $\mathrm{CO}_{2}$ e, consequentemente; a lixiviação de $\mathrm{Ca}\left(\mathrm{HCO}_{3}\right)_{2}$ com a água.

$\mathrm{Na}$ Figura 3B se observa que ao longo das coletas as concentrações de Ca no percolado reduziram-se. Resultados semelhante obtiveram por Freitas et al. (2004), que verificaram 
que as concentrações de cálcio no percolado dos lisímetros com aplicação de água residuária de suinocultura; geralmente, foram menores no final ciclo da cultura do milho do inicio.

\section{Magnésio}

A análise de variância não foi significativa para nenhum dos fatores avaliados, isto é, as concentrações de magnésio no material percolado não foram influenciadas pelas taxa de ARS nem pela adubação, tal como por suas interações, nem pelas datas de coleta.

\section{Potássio}

A análise de variância foi significativa para os fatores adubação, ARS e DAS e não significativa para a interação ARS versus $A D$.

Os tratamentos que receberam adubação na semeadura apresentaram maiores concentrações de K no percolado 133,48 $\mathrm{mg} \mathrm{L}^{-1}$, enquanto no sem adubação $84,94 \mathrm{mg} \mathrm{L}^{-1}$, isto ocorreu devido ao fato de que o K é um elemento móvel no solo e está sujeito a lixiviação. A lixiviação de potássio será maior quanto mais expressiva for a presença em solução de ânions, com menor capacidade de adsorção. Esta maior lixiviação nos tratamentos que receberam adubação química na semeadura ocorreu pelo fato de que o potássio usado na adubação foi aplicado na forma de $\mathrm{KCl}$ (cloreto de potássio), e este nutriente quando aplicado nessa forma sofre maior lixiviação do que quando aplicado na forma de $\mathrm{K}_{2} \mathrm{SO}_{4}^{-}$(sulfato de potássio), ânion com maior capacidade de absorção do que o $\mathrm{KCl}$, ou do que o $\mathrm{KAISiO}_{4}$ (kalsilita) que, além de apresentar baixa solubilidade em água contém o ânion $\mathrm{SiO}_{4}^{-}$é mais fortemente adsorvido pelo $\mathrm{H}_{2} \mathrm{PO}_{4}^{-}$.

$\mathrm{Na}$ Figura 4A pode-se observar a variação da concentração de K no material percolado, em função das taxas de ARS.

Para as concentrações de potássio no material percolado foi possível estabelecer um modelo de regressão linear crescente de acordo com as taxas de ARS.

King et al. (1985) adverte para o uso de altas taxas de aplicação de dejetos em que onde o Ca e o $\mathrm{Mg}$ podem ser deslocados dos sítios de troca pela competição de íons presentes nos dejetos, como $\mathrm{Na}, \mathrm{Ke} \mathrm{NH}_{4}^{+}$, e podem ser deslocados para camadas mais profundas por lixiviação.

Na Figura 4B pôde-se observar o comportamento das concentrações de potássio no material percolado em função das datas de coleta.

As concentrações de potássio no material percolado aumentaram ao longo do ciclo de desenvolvimento da cultura e foi possível estabelecer um modelo de regressão linear crescente de acordo com as coletas.

De acordo com Bertol et al. (2010) o potássio tem baixa reatividade com o solo podendo ocorrer uma mobilidade maior.

\section{Fósforo}

Os valores de fósforo foram maiores para os tratamentos que receberam adubação $1,01 \mathrm{mg} \mathrm{L}^{-1}$ que para o não adubado e $0,83 \mathrm{mg} \mathrm{L}^{-1}$.

Na Figura 5A se observa que as maiores concentrações de fósforo no percolado foram encontradas nos tratamentos que receberam maiores taxa de ARS. O modelo de regressão



B.



Figura 4. Valores médios de K no material percolado de acordo com as diferentes taxas de ARS (A)e de datas de coletas (B)

ajustado às concentrações de fósforo no percolado foi o linear crescente.

A mobilidade de fósforo no solo é muito pequena, razão por que as perdas por percolação em solos agricultáveis são consideradas insignificantes (Basso et al., 2005), e, em virtude disto, se observam baixas concentrações do elemento no percolado e Ceretta et al. (2003) também verificaram que o teor de fósforo disponível no solo aumentou consideravelmente com a aplicação de ARS ao longo do tempo.

Bertol et al. (2010) evidenciou que o solo que recebe dejeto líquido de suíno propicia maior suscetibilidade do solo para perda de fósforo, em relação ao solo que recebe formulados com NPK, significando, ainda que a transferência de fósforo para o solo por meio de dejeto líquido de suíno apresenta maior risco ambiental do que se essa transferência fosse feita por uma fonte inorgânica.

A análise de variância das concentrações de fósforo $\left(\mathrm{mg} \mathrm{L}^{-1}\right)$ no material percolado para o desdobramento ARS dentro de cada nível de adubação, foi significativa para o tratamento adubado.

Os resultados encontrados corroboram com obtidos por Doblinski et al. (2010) que aplicando ARS em solo cultivado com feijão, verificou que as perdas de fósforo total no solo foram incrementadas à medida que houve aumento das doses de ARS aplicadas, sendo maior para a maior taxa de $200 \mathrm{~m}^{3} \mathrm{ha}^{-1}$. Também se observou que a partir da testemunha esta quantidade foi aumentando linearmente.

$\mathrm{Na}$ Figura 5B se apresentam os valores do fósforo $\left(\mathrm{mg} \mathrm{L}^{-1}\right)$ no material percolado para o desdobramento de ARS com adubação na semeadura. 


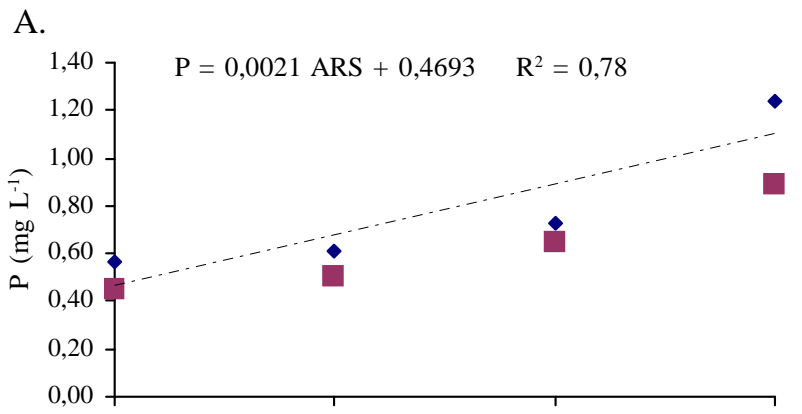

B.

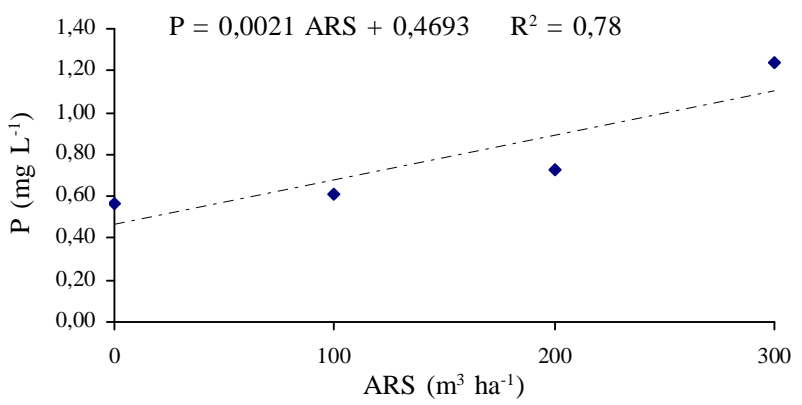

C.

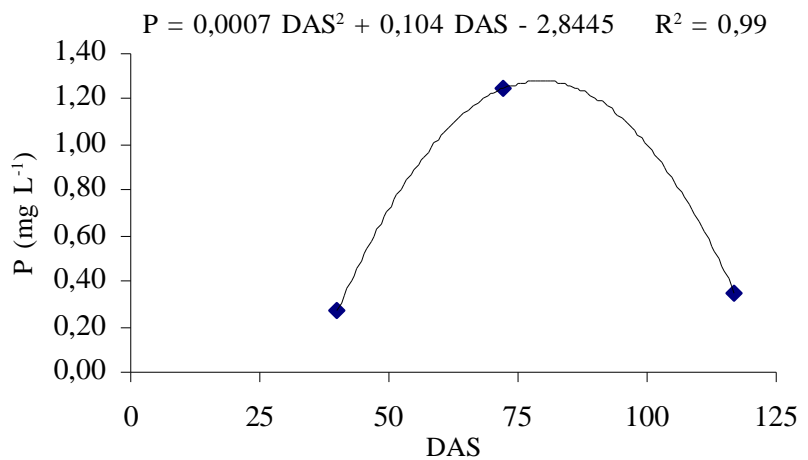

Figura 5. Concentrações de fósforo $\left(\mathrm{mg} \mathrm{L}^{-1}\right)$ no percolado de acordo com as diferentes taxas de ARS $(A)$, para 0 desdobramento de ARS com adubação na semeadura (B) e para as diferentes coletas (C)

Observa-se, na Figura 5B, que as maiores concentrações de fósforo no percolado para o desdobramento de ARS com adubação na semeadura foram encontradas nos tratamentos que receberam maiores taxa de ARS. O modelo de regressão ajustado às concentrações de fósforo no percolado foi o linear crescente.

Pode-se observar, na Figura 5C, que o modelo de regressão ajustável às concentrações de fósforo no percolado de acordo com as coletas foi o quadrático. Resultados semelhantes obteve Berwanger (2006) que verificou que nas concentrações de fósforo total no percolado com aplicação de 0, 520 e 1.040 $\mathrm{m}^{3} \mathrm{ha}^{-1}$, em cinco anos de água residuária de suinocultura na cultura do milho independem das taxas aplicadas. As maiores concentrações de fósforo foram observadas aos 79 dias após a aplicação do dejeto e os aumentos no fósforo total chegaram a 1,2 e 2,9 vezes nos tratamentos que foram aplicadas $520 \mathrm{e}$ $1.040 \mathrm{~m}^{3} \mathrm{ha}^{-1}$ de ARS, respectivamente, em relação a testemunha.

Nota-se que a percolação de fósforo no perfil do solo após a aplicação de ARS é pequena. Eghball et al. (1990), aplicando
$60 \mathrm{~kg} \mathrm{ha}^{-1}$ de fósforo em faixas observaram que a movimentação do fósforo no perfil foi de apenas $4 \mathrm{~cm}$ em três diferentes tipos de solo e contudo, a movimentação em profundidade do elemento pode ser maior quando se associam altas doses de fertilizante mineral com adição de resíduos orgânicos.

Basso et al. (2005) afirmaram que as concentrações de fósforo de 0,2 a $0,3 \mathrm{mg} \mathrm{L}^{-1}$ são consideradas ideais na água percolada para um bom desenvolvimento de plantas.

Comparando-se as perdas de fósforo desse estudo com as concentrações verificadas no trabalho de Hooda et al. (1999), verifica-se que essas estão abaixo das observadas pelos autores, que foram de 2,5 a 8,1 $\mathrm{mg} \mathrm{L}^{-1} \mathrm{em}$ áreas de pastagem natural cultivada com trevo e com a aplicação de $50 \mathrm{~m}^{3} \mathrm{ha}^{-1} \mathrm{de}$ água residuária de suinocultura.

\section{Nitrogênio}

As concentrações de nitrogênio total no percolado não foram influenciadas pela aplicação de ARS nem pela adubação. Resultados semelhantes foram encontrados por Smanhotto (2008) aplicando ARS em solos cultivados com soja, em que não observou diferenças significativas nas concentrações de nitrogênio no percolado com aplicação de água residuária de suinocultura e adubação, bem como para interação adubação ARS.

Aguiar et al. (2006) verificaram baixos conteúdos de nitrogênio total no percolado após a aplicação de resíduos bovinos e palha de arroz e indicam que a redução desse nutriente no solo não tem, como principal causa, a lixiviação, mas a forma gasosa, através do processo de mineralização e volatilização respectivamente.

Considerando que a concentração de nitrogênio total da ARS aplicada ao solo foi de $887 \mathrm{mg} \mathrm{L}^{-1}$, pode-se observar, na Figura 6, que as perdas foram pequenas, resultados discordantes encontrados por Boeira et al. (2002), em que a aplicação de altas doses de lodo de esgoto ao solo pode no entanto, liberar $\mathrm{N}$ mineral acima das necessidades de um cultivo, com risco potencial de lixiviação de nitrato no solo.

Na Figura 6 estão apresentadas as concentrações de nitrogênio $\left(\mathrm{mg} \mathrm{L}^{-1}\right)$ no percolado, em função das coletas.

O modelo de regressão estabelecido foi o linear crescente, indicando que o teor de nitrogênio no percolado aumentou ao longo do experimento.

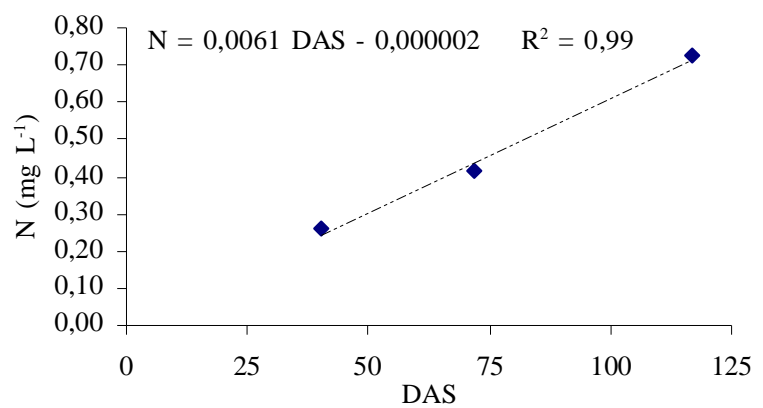

Figura 6. Concentrações de nitrogênio (mg L-1) no percolado de acordo com as diferentes coletas 


\section{Conclusões}

1. A aplicação de ARS e a adubação na semeadura não influenciaram significativamente os valores do $\mathrm{pH}$ no percolado, porém tais valores foram estatisticamente diferentes para as datas de coleta.

2. Os teores de $\mathrm{Mg}$ no percolado não foram influenciados significativamente pela aplicação de ARS, adubação e coletas.

3. Os teores de $\mathrm{P}, \mathrm{K}$ e Ca no percolado aumentaram conforme aumento das taxas de ARS e sofreram alterações dos valores ao longo das coletas.

4. O N no percolado não foi influenciado pela aplicação de ARS, porém, aumentou ao longo das coletas.

\section{LITERATURA CITADA}

Aguiar, M. I.; Lourenço, I. P.; Oliveira, T. S.; Lacerda, N. B. Perda de nutrientes por lixiviação em um ARGISSOLO Acinzentado cultivado com meloeiro. Revista Brasileira de Engenharia Agrícola e Ambiental, v.10, p.811-819, 2006.

Anami, M. H.; Sampaio, S. C.; Suszek, M.; Gomes, S. D.; Queiroz, M. M. F. Deslocamento miscível de nitrato e fosfato proveniente de água residuária da suinocultura em colunas de solo. Revista Brasileira de Engenharia Agrícola e Ambiental, v.2, p.75-80, 2008.

APHA - American Public Health Association, AWWA American Water Works Association, WEF- World Economic Forum . International nonprofit scientific and educational society dedicated to the improvement - Standard methods for the examination of water and wastewater. 20.ed. Washington: American Public Health Association, 1998. 1193p.

Barros, F. M.; Martinez, M. A.; Neves, J. C. L.; Matos, A. T.; Silva, D. D. Características químicas do solo influenciado pela adição de água residuária da suinocultura. Revista Brasileira de Engenharia Agrícola e Ambiental, v.9, p.47-51, 2005.

Basso, C. J.; Ceretta, C. A.; Poletto, R. D. N.; Girotto, E. Dejeto líquido de suínos: II - Perdas de nitrogênio e fósforo por percolação no solo sob plantio direto. Ciência Rural, v.35, p.1305-1312, 2005.

Bertol, O. J.; Rizzi, N. E.; Favaretto, N.; Lana, M. C. Phosphorus loss by surface runoff in no-till system under mineral and organic fertilization. Scientia Agrícola, v.67, p.71-77, 2010.

Berwanger, A. L. Alterações e transferências de fósforo do solo para o meio aquático com o uso de dejeto líquido de suínos. Santa Maria: UFSM, 2006. 102p. Dissertação Mestrado

Boeira, R. C.; Ligo, M. A. V.; Dynia, J. F. Mineralização de nitrogênio em solo tropical tratado com lodos de esgoto. Pesquisa Agropecuária Brasileira, v.37, p.855-862, 2002.

Brito, F. B.; Rolim, M. M.; Silva, J. A. A.; Pedrosa, E. M. R. Qualidade do percolado de solos que receberam vinhaça, em diferentes doses e tempo de incubação. Revista Brasileira de Engenharia Agrícola e Ambiental, v.11, p.318-323, 2007.
Caovilla, F. A.; Sampaio, S. C.; Pereira, J. O.; Vilas Boas, M. A.; Gomes. B. M.; Figueiredo, A. C. Lixiviação de nutrientes proveniente de águas residuárias em colunas de solo cultivado com soja. Revista Brasileira de Engenharia Agrícola e Ambiental, v.9, p.283-287, 2005.

Ceretta, C. A.; Durigon, R.; Basso, C. J.; Barcellos, L. A. R.; Vieira, F. C. B. Características químicas de solo sob aplicação de esterco líquido de suínos em pastagem natural. Pesquisa Agropecuária Brasileira, v.38, p.729-735, 2003.

Doblinski, A. F.; Sampaio, S. C.; Silva, V. R.; Nóbrega, L. H. P.; Gomes, S. D.; Dal Bosco, T. C. Nonpoint source pollution by swine farming wastewater in bean crop. Revista Brasileira de Engenharia Agrícola e Ambiental, v.14, p.87-93, 2010.

Duarte, A. S; Airoldi, R. P. S.; Folegatti, M. V.; Botrel, T. A.; Soares, T. M. Efeitos da aplicação de efluente tratado no solo: $\mathrm{pH}$, matéria orgânica, fósforo e potássio Revista Brasileira de Engenharia Agrícola e Ambiental, v.12, p.302310, 2008.

Durigon, R.; Ceretta, C. A.; Basso, C. J.; Barcellos, L. A. R.; Pavinato, P. S. Produção de Forragem em Pastagem Natural com o Uso de Esterco Líquido de Suínos. Revista Brasileira de Ciência do Solo, v.26, p.983-992, 2002.

Eghball, B.; Sander, D. H.; Skopp, J. Diffusion, adsorption and predicted longevity of banded phosphorus fertilizer in three soils. Soil Science Society American Journal, v.54, p.11611165, 1990.

EMBRAPA - Empresa Brasileira de Pesquisa Agropecuária. Centro Nacional de Pesquisa de Solos. Sistema brasileiro de classificação de solos. Brasília: EMBRAPA, 1999. 412p.

FAO - Food and Agriculture Organization. Lisimeters. Rome: FAO, 1982. 68p. Irrigation and Drainage Paper, 39).

Ferreira, D. F. Análise estatística por meio do SISVAR (Sistema para Análise de Variância) para Windows versão 4.0. In: Reunião Anual da Região Brasileira da Sociedade Internacional de Biometria, 45, 2000, São Carlos. Anais... São Carlos: UFSCar, 2000. p.255-258.

Freitas, W. S.; Oliveira, R. A.; Cencon, P. R.; Pinto, F. A.; Galvão, J. C. C. Efeito da aplicação de água residuária de suinocultura sobre a produção de milho para silagem. Revista Brasileira de Engenharia Agrícola e Ambiental, v.8, p. 120-125, 2004.

Furtini Neto, A. E.; Vale, F. R.; Resende, A. V.; Guilherme, L. R. G.; Guedes, G. A. A. Fertilidade do solo. Lavras: UFLA/ FAEPE, 2001. 261p.

Gomes, E. R. S.; Sampaio, S. C.; Corrêa, M. M.; Vilas Boas, M. A.; Alves, L. F. A.; Sobrinho, T. S. Movimento de nitrato proveniente de água residuária em colunas de solos. Engenharia Agrícola, v.24, p.557-568, 2004.

Hooda, P. S.; Moynagh, M.; Svoboda, I. F.; Edwards, A. C.; Anderson, H. A.; Sym, G. Phosphorus loss in drainflow from intensively managed grassland soils. Journal of Environmental Quality, v.28, p.1235-1242, 1999.

King, L. D.; Westerman, P. W.; Cummings, G. A.; Overcash, M. R.; Burns, J. C. Swine lagoon effluent applied to 'Coastal' Bermudagrass: II Effects on soil. Journal of Environmental Quality, v.14, p.14-21, 1985. 
Prior, M.; Smanhotto, A.; Sampaio, S. C ; Nóbrega, L. H. P. ; Opazo, M. A. U.; Dieter, J. Acúmulo e percolação de fósforo no solo devido a aplicação de água residuária da suinocultura na cultura do milho (Zea mays L.). Pesquisa Aplicada e Agrotecnologia, v.2, p.89-96, 2009.

Queiroz, F. M.; Mattos, A. T.; Pereira, O. G.; Oliveira, R. A. Características químicas de solo submetidos ao tratamento com esterco líquido de suínos e cultivados com gramíneas forrageiras. Ciência Rural, v.34, p.14871492, 2004.
Smanhotto, A. Efeito da aplicação de água residuária de suinocultura em solo cultivado com soja. Botucatu: UNESP, 2008. 120p. Tese Doutorado

Smanhotto, A.; Sousa, A. P.; Sampaio, S. S.; Nóbrega, L. H. P.; Prior, P. Cobre e zinco no material percolado e no solo com a aplicação de água residuária de suinocultura em solo cultivado com soja. Engenharia Agrícola, v.30, p.347-357, 2010.

Tedesco, M. J.; Giianello, C.; Bissani, C. A.; Bohnem H.; Volkweiss, S. J. Análise de solo, plantas e outros materiais. Porto Alegre: UFRGS, 1995. 174p. 